\title{
Vitelliform macular dystrophy and butterfly-shaped epithelial dystrophy: a continuum?
}

\author{
ISAAC GUTMAN, JOSEPH B. WALSH, AND PAUL HENKIND
}

From the Department of Ophthalmology, Montefiore Hospital \& Medical Center/Albert Einstein College of Medicine, 111 East 210th Street, Bronx, New York 10467, USA

SUMMARY We report the case of a 22-year-old white female who presented for a routine ocular examination and displayed Best's disease in her right eye and butterfly-shaped macular dystrophy in her left eye. These diagnoses were confirmed by fluorescein angiography, EOG, and ERG. The fact that these 2 disorders are present in one person suggests that they are only different manifestations of the same underlying disease process.

Vitelliform macular dystrophy (Best's disease) and butterfly-shaped epithelial dystrophy of the macula (Deutman's dystrophy) have been described as 2 separate heredodystrophic diseases affecting the retinal pigment epithelium and the outer retina. ${ }^{12} \mathrm{We}$ report a patient who has vitelliform macular

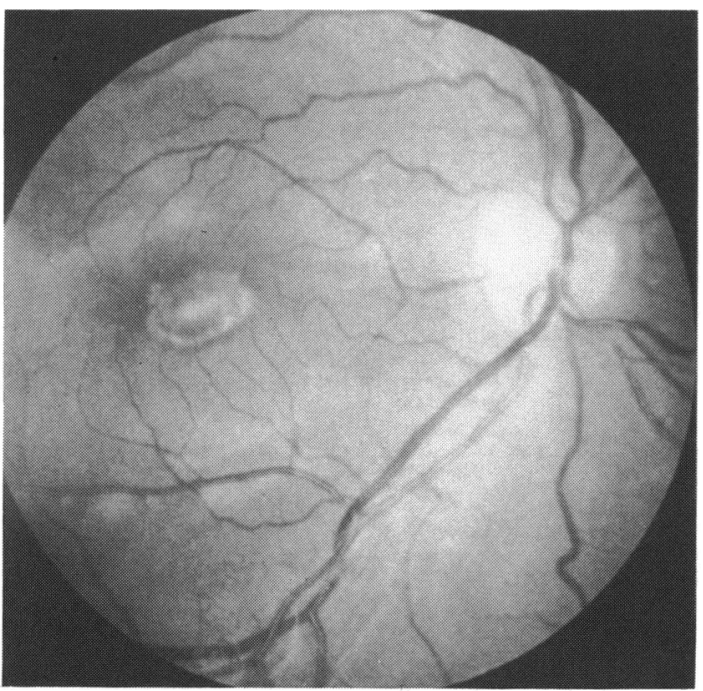

Fig. 1 Fundus photograph OD: Anoval, well-demarcated, yellowish, macular lesion, 3/4 disc diameter in size.

dystrophy (VMD) in the right eye and butterflyshaped epithelial dystrophy (BED) in the left eye.

This is the first case that suggests these 2 rare Correspondence to I. Gutman, MD. diseases may be different manifestations of the same heritable disorder.

\section{Case report}

The patient is a 22-year-old white female who

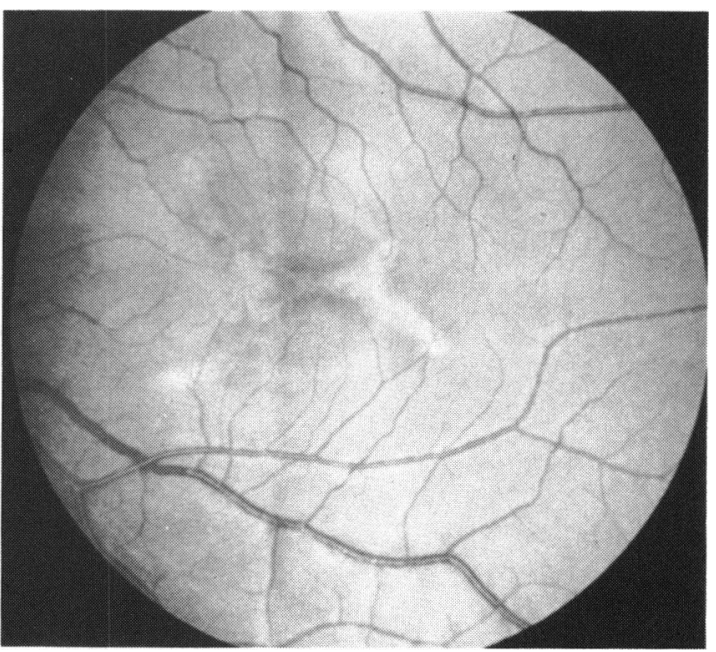

Fig.2 Fundus photograph OS: A butterfly-shaped, hyperpigmented lesion, about 3 disc diameters in size, in the macular region.

presented to the eye clinic for a routine examination. She had no visual complaints. Medical and ocular histories were unremarkable. Ocular examination showed an uncorrected visual acuity of $6 / 6(20 / 20)$ 


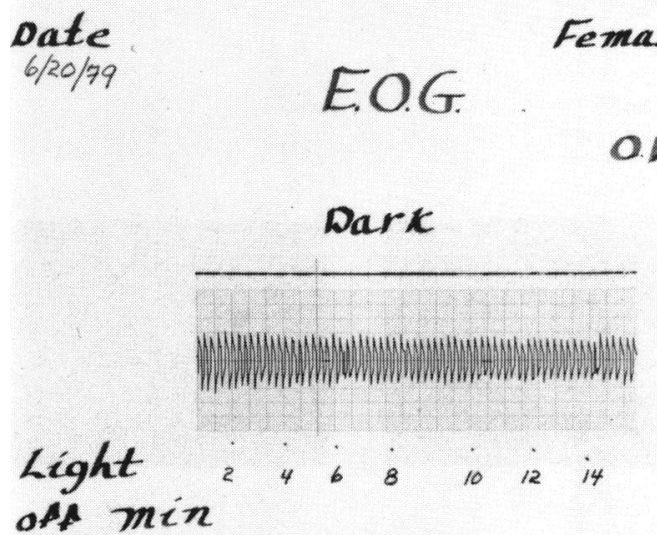

\section{Light}

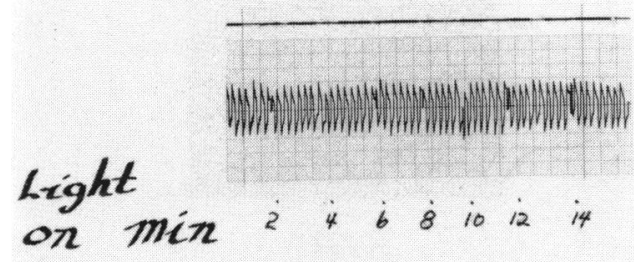

Fig. 3a

Fig. 3 EOG shows no light rise: (a) $O D,(b) O S$

$\mathrm{J} 1+$ in each eye (OU), tension by applanation 16 $\mathrm{mmHg}$, and ocular motility full OU. By slit-lamp biomicroscopy the lids, conjunctivae, and anterior segments were normal OU. Pupils were $2.5 \mathrm{~mm}$, round, equal and had normal light and accommodative responses; lenses and vitreous bodies were clear OU. Examination of the fundi revealed normal discs, blood vessels, and periphery. The macula of the right eye showed a 3/4-disc-diameter oval, yellowish, well-demarcated lesion at the level of the retinal pigment epithelium (RPE) without visible alteration of the overlying retina (Fig. 1). The left macula showed a 3-disc-diameter, $\mathrm{H}$-shaped, hyperpigmented lesion of the RPE with an intact overlying retina (Fig. 2).

Laboratory data: Visual fields (Goldmann) - full OU. Colour vision (American Optical-Hardy, Rand, and Rittler pseudoisochromatic)-normal OU. Amsler grid-normal OU. Electro-oculogram (EOG)—LP/DT:1/1 OU (Figs. 3a, 3b). Electroretinogram (ERG)—normal OU (Figs. 4a, 4b). Fluorescein angiography-blockage of background fluorescence in the area of RPE changes without leakage (Figs. 5a, 5b).
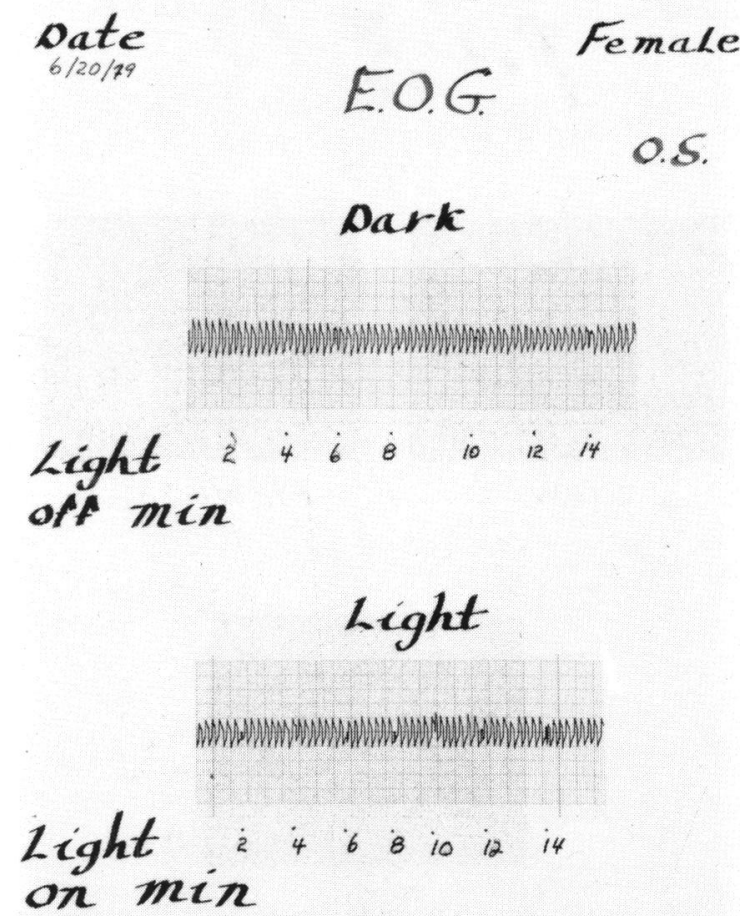

Fig. 3b

A 24-year-old sister had 6/6 (20/20) visual acuity OU and ophthalmoscopically had the clinical picture of an extrafoveal vitelliform dystrophy OU. No further diagnostic procedures were allowed, and other family members were not available for examination.

\section{Discussion}

Butterfly-shaped epithelial dystrophy of the macula (BED) is an extremely rare autosomal dominant disease, first described by Deutman et al. ${ }^{2}$ They described a pedigree with affected members, 4 brothers and one son, all of whom had good visual acuity. By funduscopy the macular area showed a peculiar bilateral butterfly-shaped hyperpigmentation. These pigmentary changes appeared to be at the level of the RPE.

There are no clinicohistopathological correlations of this disease and the prognosis is unknown.

Vitelliform macular dystrophy (VMD) is an autosomal dominant macular disorder first described by F. Best in $1905 .{ }^{13}$ Many cases have been recorded. 
Date

Female Date

Female
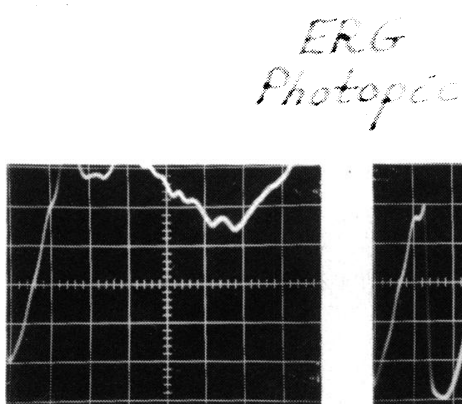

s/6W

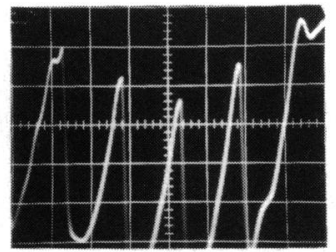

$5 / 6 \mathrm{~W} F 30 / \mathrm{sec}$.
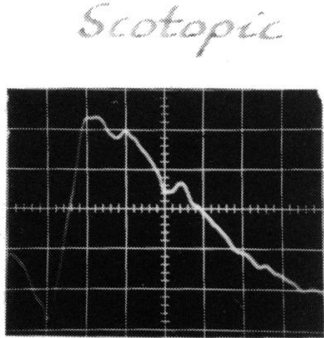

$5 / 8$

Fig. 4a

Fig. $4 \mathrm{~b}$

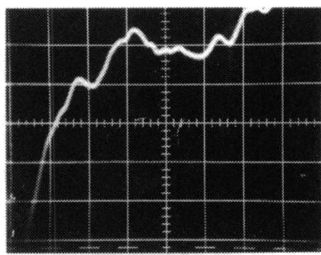

S/bul
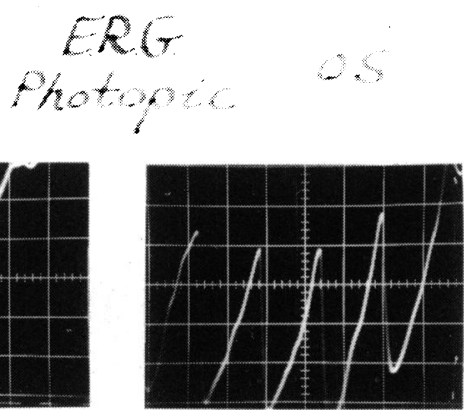

$5 / 6 \mathrm{WF} 30 / \mathrm{sec}$.
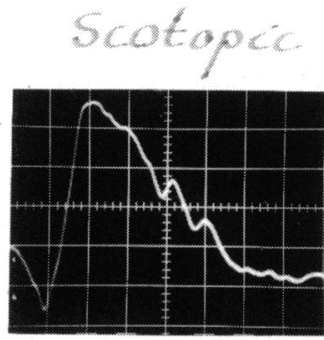

$S / B$

Fig. 4 ERG under standard conditions is normal: (a) OD, (b) OS. Recordings made using a Grass PS 22 Photostimulator. Photopic: single flash and flicker fusion at 30/s. Scotopic: recruitment response with a blue flash.

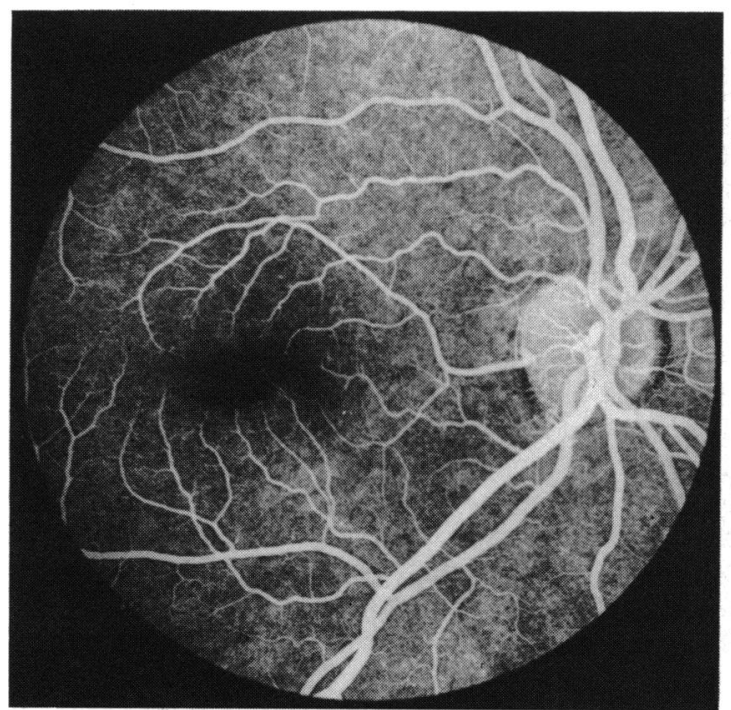

Fig. 5a

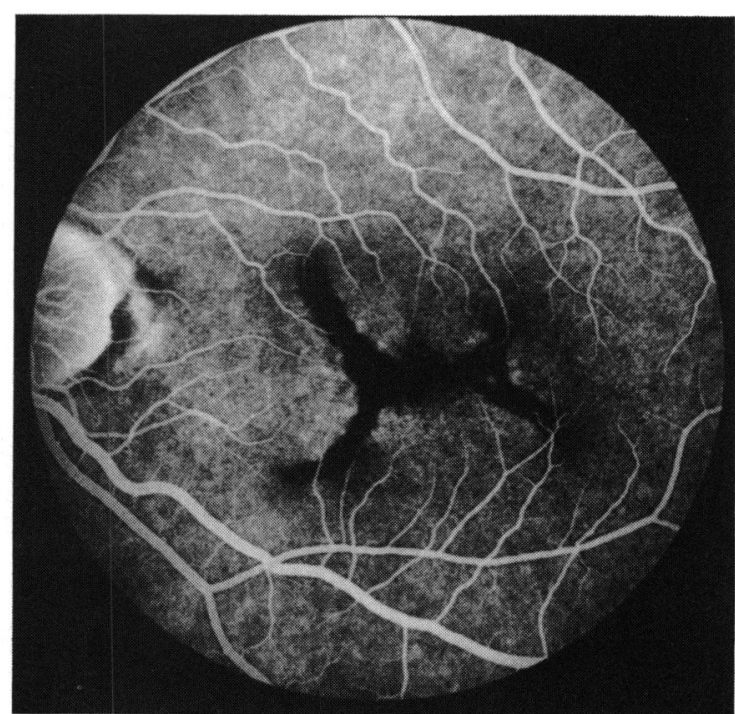

Fig. 5b

Fig. 5 Fluorescein angiogram in early venous phase shows blockage of background fluorescence in the area of the fundus lesion: (a) $O D$, (b) $O S$. 
Table 1 Comparision of vitelliform macular and butterfly-shaped dystrophy

\begin{tabular}{|c|c|c|}
\hline & $\begin{array}{l}\text { Vitelliform macular } \\
\text { dystrophy }\end{array}$ & $\begin{array}{l}\text { Butterfly epithelial } \\
\text { dystrophy }\end{array}$ \\
\hline $\begin{array}{l}\text { Mode of inheritance } \\
\text { Visual acuity: }\end{array}$ & Autosomal dominant & Autosomal dominant \\
\hline (a) presentation & Normal & Normal \\
\hline (b) follow-up & May diminish & Unknown \\
\hline \multicolumn{3}{|l|}{ Colour vision: } \\
\hline (a) presentation & Normal & Normal \\
\hline (b) follow-up & May diminish & Unknown \\
\hline Visual fields & Normal & Normal \\
\hline $\begin{array}{l}\text { Fluorescein } \\
\text { angiography }\end{array}$ & $\begin{array}{l}\text { Blockage of } \\
\text { background } \\
\text { fluorescence by the } \\
\text { lesion }\end{array}$ & $\begin{array}{l}\text { Blockage of } \\
\text { background } \\
\text { fluorescence by the } \\
\text { hyperpigmented area }\end{array}$ \\
\hline ERG & Normal & Normal \\
\hline EOG & Abnormal & Abnormal \\
\hline
\end{tabular}

Ocular examination is normal except for funduscopy. Yellowish, oval, sharply demarcated 'cystic' lesions are seen bilaterally at the level of the RPE. They may be present at birth but are typically discovered between ages 3 and $15 .^{4}$ At the first stage of the disease the lesion is well demarcated and uniform in appearance, and the overlying retina appears normal. At this stage visual acuity is usually normal. This vitelliform 'cyst' may persist for a number of years but characteristically breaks up in the second or third decade. As it becomes less uniform and pigmentary changes occur, the lesion transforms from an 'eggyolk' to a 'scrambled-egg' appearance, and visual acuity diminishes to between 20/50 and 20/200. Rarely, subretinal neovascularisation may occur, and macular scarring is the end stage.

At the 1980 meeting of the Association for Research in Vision and Ophthalmology Weingeist, Kotbrin, and Watzke presented the histopathology of a 29-year-old patient with VMD in the 'scrambledegg' stage. ${ }^{5}$ Light and electron microscopy indicated that VMD is a generalised retinal pigment epitheliopathy which results in abnormal accumulation of lipofuscin granules within the RPE.

VMD and BED were initially described as separate clinical entities. As more became known about them, some similarities have been noted. ${ }^{67}$ The same is true for another group of diseases of the retinal pigment epithelium, including dystrophia reticularis, dystrophia macroreticularis, reticular pigment dystrophy, butterfly dystrophy, and fundus pulverulentus. In all of these entities the pathogenesis is unknown. The visual prognosis is good, and different patterns of these reticular pigmentations may be seen in the same family. These diseases have been included under the title of 'pattern dystrophies.' This term was coined independently by Hsieh et al. ${ }^{6}$ and Marmor and Byers.?

There are similarities between VMD and BED upon testing (Table 1). In our patient BED and VMD are present in opposite eyes. This strongly suggests that VMD and BED may be different expressions of the same disease process. Proof of this hypothesis will depend on a careful examination of affected pedigrees and histopathological studies.

\section{References}

1 Barkman Y. A clinical study of a central tapetoretinal degeneration. Acta Ophthalmol (Kbh) 1961; 39: 663-71.

2 Deutman AF, Van Blommestein JDA, Henkes HE, Waardenburg PJ, Solleveld-Van Dreist E. Butterfly-shaped pigment dystrophy of the fovea. Arch Ophthalmol 1970; 83: 558-69.

3 Krill AE. Vitelliruptive macular dystrophy. In: Krill AE, ed. Hereditary Retinal and Choroidal Diseases. Hagerstown: Harper and Row, 1977; 2: 665-704.

4 Deutman AF. Electro-oculography in families with vitelliform dystrophy of the fovea. Arch Ophthalmol 1969; 81: 305-15.

5 Weingeist TA, Kotbrin JL. Watzke RC. Histopathology of Best's vitelliform macular dystrophy. ARVO Abstracts May 1980: 259.

6 Hsieh CR. Fine BS. Lyons JS. Patterned dystrophies of the retinal pigment epithelium. Arch Ophthalmol 1977; 95: 429-35.

7 Marmor MF. Byers B. Pattern dystrophy of the pigment epithelium. Am J Ophthalmol 1977; 84: 32-44. 